\title{
Big Five in University Students in Relation to Psychological and Entrepreneurial Competences
}

\author{
Iveta Kmecová ${ }^{1}$ and Alena Kajanová ${ }^{2}$ \\ ${ }^{1}$ Department of Human Resource Management, Institute of Technology and Business in Ceske \\ Budejovice, Czech Republic \\ ${ }^{2}$ Institute of Technology and Business in Ceske Budejovice, Czech Republic
}

\begin{abstract}
The objective of the research was to find and analyse the dependence factors of the individual personality. For the purpose of the analysis, students of two higher education institutions in the South Bohemian Region, the Czech Republic, were chosen. The students were from different fields of study, men and women, of different age. The research further dealt with the dependency of the Big Five factors on the positive and negative stress management strategies. The research results can be used for further studies that would be a contribution to theory as well as for the individualization of the approach to concrete groups or individual students.
\end{abstract}

Keywords: NEO-FFI, entrepreneurial competences, big five theory, stress management strategies

\section{Introduction}

The aim of our paper is to analyze the relationship a) between basic personality characteristics according to Big Five measured using the NEO-FFI questionnaire and selected sociodemographic variables and then b) between Big five personality characteristics and coping strategies according to SVF-78 and all students of the University of Technology and economic in Č. Budějovice (Czech Republic). We proceeded from the following hypotheses: H1: There is a relationship between the NEO-FFI dimensions and the SVF-78 coping strategies. H2: There is a difference in the dimensions of NEO-FFI according to the field studied. H3: There is a difference in the dimensions of NEO-FFI according to age.

\section{Theoretical Background}

NEO Five Factor Inventory (NEO-FFI) is a convenient tool for many industrial and organizational applications, including candidate screening and placement, performance prediction - as well as wide applications in research. NEO-FFI is a quick and efficient tool that has found successful applications in a number of applied and research field. The study defines term NEO Five-Factor Inventory (NEO-FFI) as a shortened version of a solid empirically-validated NEO Personality Inventory-Revised, an implementation of the five- 
factor model (FFM) of personality. Originally intended to provide a quick measure for screening and introductory purposes, NEO-FFI gained a position in a number of applied and research fields [1]. The Topic NEO Big Five has long been a concern for many researchers; NEO Five-factor inventory has been published in a number of books and journals, for example in [1] and in others. NEO Five-Factor Inventory (NEO-FFI) test is one of the latest developments in the field of personality measurement, intended to assess emotional, interpersonal, experiential, attitudinal, and motivational styles of individuals. These styles represent the empirically discovered five-factor model (FFM) of the human personality. NEO-FFI being a much shorter version of a mainstream NEO Personality Inventory-Revised (NEO PI-R), has its specific advantages and disadvantages that are discussed in this paper [1]. A meta-analysis reports a number of studies where NEO-FFI was used to predict academic performance (GPA, course grade, and average exam grade) with Conscientiousness scale most consistently linked to post-secondary academic success. NEO-FFI is a shortened version of the NEO Personality Inventory-Revised, an implementation of a successful, and extensively empirically-validated five-factor model of human personality. In accordance to the two methods of personality assessment outlined below-personality questionnaire and peer rating-NEO-FFI offers two observer-rating forms (for rating men and women) along with the standard self-report form, as well as a college-age self-report form. All 60 items of the NEO-FFI test require a response rated on the five-point Likert scale. The published expects most people to complete NEO-FFI within 15 minutes with scoring taking only 1 or 2 minutes [2]. The study holds the idea that the NEO-FFI-3 can help understand respondent's basic emotional, interpersonal, experiential, attitudinal, and motivational styles. It can also help quickly develop rapport with respondent, provide meaningful feedback and insight that will help our respondent/client develop greater self-understanding. The NEO Five-Factor Inventory-3 (NEO-FFI-3), is the updated version of the NEO-FFI - a 60item version of the NEO-PI-3. It provides a quick, reliable, and accurate measure of the five domains of personality and is particularly useful when time is limited and when global information on personality is needed [3]. Another result outlines in their other studies: In vocational counselling, the NEO PI-R can supplement measures of vocational interests and abilities, especially by calling attention to the client's strengths and weaknesses in adjustment and motivation. Use of the NEO Job Profiler a tool designed to help identify the personality requirements of different occupations is illustrated in the police selection sample. Together, the NEO Job profiler and NEO PI-R can help determine the optimal match between person and occupation. The NEO-FFI test is published in 9 foreign languages (including British English) and has validated versions available in other 25 languages [3]. Author describes the use of NEO-FFI test as a tool for quick individual personality testing in counselling and clinical setting but there is already a large body of research reporting use of this test in educational, organizational domains. [3, 4] Another study informs about results of research on a sample of 335 adult respondents. This study deals with the analyse of NEO Five-Factor Inventory too $[5,6]$. Next study reported the significant correlations between NEO-FFI Extraversion and four different measures of creativity. Almost $50 \%$ of the variance in divergent thinking could be accounted by the NEO-FFI factors, while intelligence measured by Wonderlic Personnel Test provided no incremental variance in creativity scores [6]. Interesting is the studies $[7,8]$ is that the personality traits of treatment-seeking problem gamblers have been compared to healthy control groups in several studies and, although there is consistent evidence for high Neuroticism and low Conscientiousness in problem gamblers, past results may have been affected by selection bias. This study replicated these findings in a correlational design. The participants were nontreatment-undergraduate students who were screened for excessive and potentially addictive self-defeating behaviours. The Shorter Promis Questionnaire and the NEO PI-R were completed by undergraduate students at two Canadian universities $(\mathrm{N}=369)$. Scores on the gambling subscale showed modest but 
statistically significant correlations with high Neuroticism, low Agreeableness, and low Conscientiousness [9]. Another study evaluated the latent structure of the NEO Five-Factor Inventory (NEO FFI) and relations between the five-factor model (FFM) of personality and dimensions of DSM-IV anxiety and depressive disorders (panic disorder, generalized anxiety disorder [GAD], obsessive - compulsive disorder, social phobia [SOC], major depressive disorder [MDD]) in a large sample of outpatients $(\mathrm{N}=1,980)$ [10]. Other study reports large positive correlation between NEO-FFI Extraversion and emotional intelligence, an array of social and emotional skills that help people understand emotions of other people, as well as monitor their own feelings [11]. Goal of the next study was investigated with the change and stability of the Big-Five personality factors measured on a short scale. Fifteen similar studies using longer instruments were reviewed. In this study 7554 participants aged between 16 and 92 years completed a short 15 item FFM inventory twice six years apart in a large British sample. Participants were divided into six age groups and the results were broadly similar. Correlational analysis showed all five personality factors were considerably stable over six years after controlling for gender and age $(r=0.47$ to $r=0.60, p<.001)$. Implications and limitations of using short scales particularly problems of measurement invariance, are acknowledged [12]. The next paper deals with the popular NEO Personality InventoryRevised (NEO-PI-R) has a short form - the NEO Five-Factor Inventory (NEO-FFI) - that taps the five broad factors with fidelity and reliability. In this study, 13 item clusters were found to replicate across halves of a sample of self-descriptions by adults $(\mathrm{N}=732)$. Thirteen factor-analytically derived scales were developed for the item clusters. The scales demonstrated reliability and factor structure comparable to that of the 30 facet scales of the NEO-PI-R. Correlation and multiple regression analyses showed that the content coverage of the 13 scales has high overlap with that of the NEO-PI-R facet scales [13]. Analyses of variants of the FFM revealed that only the unrestricted exploratory factor model showed acceptable fit as well as replicability across gender and educational level the goal of the paper was to identify changes in self and peer evaluations of personality among team members using the Five Factor Model. Multidisciplinary teams of five students in an undergraduate research design project-based course were used to evaluate their own and their peer's personalities over the course of one semester. Results showed that team members' evaluations of their own personalities did not change significantly through four iterations. Team member's evaluations of their peers did change for Neuroticism, Agreeableness, and Extraversion [14]. The study reports result of a research of coping strategies identified in students in two different study modes: full-time students and part-time students. The SVF78 stress coping inventory was administered. The relationship of SVF-78 subscales to the variable study mode (full-time, part-time) was investigated. As for the statistical procedure, Levene's Test for Equality of Variances and two independent sample $t$ tests were used. The most important finding shown by results of this study is a higher usage of the tree optimal coping strategies - situation control, reaction control and positive self-instructions - by parttime students. Part-time students also use the minimization strategy more frequently and the resignation strategy less frequently than full-time students. The study has some limitations, because the sample is not representative - subjects were students of the Faculty of Economics and Management [15]. Authors of the next paper are concerned with the efficiency of the lessons with the special focus on an effect of personality variables, namely extraversion and neuroticism, on preference of stress coping strategies. The issue of relationship between extraversion resp. neuroticism and use of stress coping strategies by undergraduate students at Czech University of Life Sciences (CULS) ( $\mathrm{n}=109)$ was investigated. The data were collected with the use of standardized questionnaires SVF 78 and EOD. The mutual relationship of the variables was tested by Spearman's correlation coefficient. The results indicate association of negative coping strategies in general with neuroticism and positive strategies in general with extraversion. Practical implications of the findings are discussed 
and interventions for mental health reinforcement are recommended. The questionnaire Stress Management Strategy SVF 78 and its detailed results will be the subject of the forthcoming contribution [16].

\section{Methodology}

The research tool was the NEO Five-factor personality inventory questionnaire [17]. NEOFFI test represents one of the latest trends in the field of measuring personality traits, aiming at assessing emotional, interpersonal, experience, attitude and motivational styles of individuals [1]. The Five Factor Model (FFM) of personality has become a popular benchmark in terms of personality metrics [3]. This five-factor model measures a personality using five traits: openness to experience, conscientiousness, extraversion, agreeableness, and neuroticism.

Next, we examined the correlation relationship (the statistical dependence of two quantitative variables), specifically the relationship of two main domains of the SVF-78 questionnaire positive and negative coping strategies and dimensions of the NEO-FFI. The SVF-78 questionnaire (Stress coping style) was developed by Wilhelm Janke and Gisela Erdmann (2002) It is a multi-dimensional self-observation inventory capturing the individual tendencies to use various methods of coping with stress in stressful situations. Together with the NEO-FFI questionnaire, the SVF-78 was a part of a research project implemented within an internal grant competition. The interpretation of the detailed results obtained from the analysis of SVF 78 (Stress coping style) questionnaire will be a subject of another study [18].

The sample consisted of 277 students of the Institute of Technology and Business (ITB) in Ceske Budejovice (South Bohemian Region) in both full-time and part-time forms of study (at the age ranging between 19 and 54), with $\mathrm{m}=27$ years, studying various fields of study: Mechanical Engineering (24.6 \% respondents), Logistics (10.9\%), Economics (59.4\%) and Civil Engineering $(5.1 \%)$. The questionnaire was anonymous and it was completed in accordance with ethical principles and its completing was voluntary. The questionnaire was supplemented with several more questions focusing on socio-demographic indicators - sex, age, and field of study of the students. The data was then statistically processed by the SPSS programme at $95 \%$ significance level. After performing the normality test and ensuring the normality of the data, the following statistical parametric tests were used: t-test for two independent groups, ANOVA and correlation.

\section{Results}

In the sample mentioned above, the highest mean values were obtained in the case of the "conscientiousness" dimension (32.509). On the other hand, the lowest value was for the dimension "openness to experience" (22.054). The highest standard deviation was detected in the case of the dimension "extraversion", which indicates a large diversity of the sample in terms of this dimension (Table 1).

Table 1. NEO-FFI dimensions, basic descriptive statistics

\begin{tabular}{|c|c|c|c|c|}
\hline & Minimum & Maximum & Mean & STD \\
\hline Neuroticism & .00 & 46.00 & 22.054 & 8.122 \\
\hline Extraversion & .00 & 48.00 & 31.271 & 8.195 \\
\hline Openness to & .00 & 44.00 & 25.433 & 6.646 \\
\hline
\end{tabular}




\begin{tabular}{|c|c|c|c|c|}
\hline experience & & & & \\
\hline Agreeableness & .00 & 42.00 & 29.404 & 6.701 \\
\hline Conscientiousness & .00 & 48.00 & 32.509 & 7.680 \\
\hline
\end{tabular}

Source: Own processing.

Table 2 shows testing the NEO-FFI dimensions in relation with the sex of the respondents. For testing, an independent sample t-test was used, which showed that there is a significant difference between the sexes in the case of "extraversion" ( $p=0.004)$, "agreeableness" ( $p$ $<0.000)$ and "conscientiousness" ( $p<0,000)$. In the case of "extraversion", women achieved a higher mean score than men (32.631 for women and 29.797 for men). Also, in the case of “agreeableness", women's score was higher than men's score (31.319 to 27.331), as well as in the case of "conscientiousness" (34.722 for women and 30.113 for men).

Table 2. Relationship between NEO-FFI dimensions and sex

\begin{tabular}{|c|c|c|c|c|c|}
\hline Dimension & Sex & Mean & $\begin{array}{c}\text { Std. } \\
\text { Deviation }\end{array}$ & $\mathrm{t}$ & Sig. (2-tailed) \\
\hline \multirow{2}{*}{ Neuroticism } & Male & 21.278 & 8.384 & -1.532 & .127 \\
\cline { 2 - 6 } & Female & 22.771 & 7.834 & -1.528 & .128 \\
\hline \multirow{2}{*}{ Extraversion } & Male & 29.797 & 8.489 & -2.915 & $\mathbf{. 0 0 4}$ \\
\cline { 2 - 6 } & Female & 32.632 & 7.695 & -2.904 & $\mathbf{. 0 0 4}$ \\
\hline \multirow{2}{*}{$\begin{array}{c}\text { Openness to } \\
\text { experience }\end{array}$} & Male & 24.902 & 7.025 & -1.279 & .202 \\
\cline { 2 - 6 } & Female & 25.923 & 6.261 & -1.273 & .204 \\
\hline \multirow{2}{*}{\begin{tabular}{c} 
Agreeableness \\
\cline { 2 - 6 }
\end{tabular}} & Male & 27.331 & 7.036 & -5.175 & $\mathbf{. 0 0 0}$ \\
\cline { 2 - 6 } & Female & 31.319 & 5.769 & -5.135 & $\mathbf{. 0 0 0}$ \\
\hline \multirow{2}{*}{ Conscientiousness } & Male & 30.113 & 8.240 & -5.222 & $\mathbf{. 0 0 0}$ \\
\cline { 2 - 6 } & Female & 34.722 & 6.395 & -5.171 & $\mathbf{. 0 0 0}$ \\
\hline
\end{tabular}

Source: Own processing.

The relationship between the age of the respondents and the NEO-FFI dimensions was tested using the Analysis of Variance (ANOVA) test. In this case, no statistically significant dependence has shown (see Table 3). It follows from the results that according to the NEOFFI, personal traits do not depend on age.

Table 3. Relation between NEO-FFI dimensions and age

\begin{tabular}{|c|c|c|}
\hline Dimension & F & Sig. \\
\hline Neuroticism & 1.524 & .043 \\
\hline Extraversion & 1.275 & .159 \\
\hline Openness to experience & .913 & .603 \\
\hline Agreeableness & 1.087 & .352 \\
\hline Conscientiousness & 1.748 & $\mathbf{. 0 1 1}$ \\
\hline
\end{tabular}


Source: Own processing.

In terms of identifying the relation between the dimensions and the studied field (tested using ANOVA), the only significant relationship was detected in the case of the "conscientiousness" dimension ( $p=0.005 ; \mathrm{F}=4.387)$. As Table 4 shows, the mean value for mechanical engineering was 31.779, while it was 30.3 for logistics, 29.433 for economics, and 30.429 for civil engineering. The highest score was thus achieved in the case of mechanical engineering, while students of economics appear to be least conscientious.

Table 4. Relation between NEO-FFI dimensions and studied field

\begin{tabular}{|c|c|c|}
\hline Dimension & F & Sig. \\
\hline Neuroticism & 1.250 & .292 \\
\hline Extraversion & 3.725 & .012 \\
\hline Openness to experience & .707 & .549 \\
\hline Agreeableness & 3.832 & .010 \\
\hline Conscientiousness & 4.387 & $\mathbf{. 0 0 5}$ \\
\hline
\end{tabular}

Source: Own processing.

Table 5. Correlation of two main domains of SVF-78 questionnaire and NEO_FFI dimensions

\begin{tabular}{|c|c|c|c|c|}
\hline & SVF POZ & & SVF NEG & \\
\hline $\begin{array}{c}\text { NEO-FFI } \\
\text { dimension }\end{array}$ & $\mathrm{P}$ & $\mathrm{r}$ & $\mathrm{p}$ & $\mathrm{r}$ \\
\hline Neuroticism & $\mathbf{0 . 0 0 0}$ & -0.323 & $\mathbf{0 . 0 0 0}$ & 0.703 \\
\hline Extraversion & $\mathbf{0 . 0 0 0}$ & 0.408 & $\mathbf{0 . 0 0 0}$ & -0.363 \\
\hline $\begin{array}{c}\text { Openness to } \\
\text { experience }\end{array}$ & $\mathbf{0 . 0 0 0}$ & 0.254 & 0.156 & -0.086 \\
\hline Agreeableness & 0.028 & 0.132 & 0.562 & 0.562 \\
\hline Conscientiousness & $\mathbf{0 . 0 0 0}$ & 0.287 & $\mathbf{0 . 0 0 0}$ & -0.308 \\
\hline
\end{tabular}

Source: Own processing.

Table 5 shows the correlation of the two main SVF-78 questionnaire domains results positive and negative coping strategies and NEO-FFI dimensions. Significant correlations have been detected in the case of positive strategies and all NEO-FFI dimensions. In terms of negative strategies, only neuroticism, extraversion, and conscientiousness correlated. In all cases, these were rather weak correlations.

\section{Discussion}

The results show certain trends. University students achieved a high number of points in the 
questionnaires especially for conscientiousness, while the lowest scores were achieved in openness to experience. In Czech context, these results can be interpreted among the university students by the fact that university studies are a certain traditional basis for entry into life, to which the students are motivated both by their parents and people around them. Thanks to free studies, higher education is perceived by society as a standard way for the students of secondary schools. Lower scores for openness to experience can thus be caused by the above-mentioned "standard way" [19]. However, for successful study, the ability of students to conscientiously fulfil the requirements is necessary. Therefore, high scores for conscientiousness are expected. It is also necessary to take into account time, financial and psychic (stress) burden placed on university students, but the students did not show higher scores or neuroticism associated with stress. Although the research does not deal with the personality traits, the results of the questionnaire may affect these negative factors [20].

The dependence of the individual personality traits on the sex was confirmed for conscientiousness, agreeableness, and extraversion. In this case, women an achieved higher score but also a lower standard deviation [21]. These results partially correspond to where the female students achieved higher scores in conscientiousness and agreeableness compared to male students. However, correlation with neuroticism was not detected. In the case of extraversion, the female students showed a lower score that the male students. This could be due to different types of universities, as included also medical and social-type of schools and pedagogical schools, which are popular rather with female students in the Czech Republic $[19,21]$. The results of the individual studies show different outcomes (Rubinstein, 2005), which can point to the differences between the male and female students of the individual fields of study in higher education institutions [19].

In terms of the age of the students, no significant dependence was confirmed, which corresponds with the conclusion that the age factor does not influence the individual personality traits of students. However, it is questioned whether a higher score in conscientiousness and extraversion would be achieved if a higher number of older students were included [22].

When investigating the dependence of personality traits on a field of study, dependence was confirmed only for conscientiousness. In this case, the highest score was achieved by mechanical engineering students. Civil engineering and logistics students achieved a lower score, while the lowest number of points was achieved by economics students. This indicates that students of economics are less conscientious than students in technical fields. However, it is necessary to take into account that the representation of men and women in individual fields of study is not even. In the Czech Republic, students of technical fields are mostly men [23]. Given that women showed higher score in conscientiousness than men but men showed higher standard deviation, it can be concluded that male students studying economic fields achieved lower score than male students in technical fields, which can be influenced by the expected roles of these student's bone.

For verification of this conclusion, further investigation is necessary. This research could help create learning processes that would make use of the strengths of students in individual fields of study [24].

Finally, when comparing the results of Big Five personality traits with the stress management strategy (SVF-78) questionnaires, there was a correlation between positive strategies with all kinds of personality traits, which does not have to be considered decisive, as these results can be distorted by individual students' self-assessment that does not necessarily correspond with the reality. In the case of negative stress management strategies, there was a correlation with neuroticism, extraversion, and conscientiousness. This partly corresponds with the specific personality traits. Neuroticism can be seen as a negative trait; its correlation with negative 
stress management strategies was thus expected. Extraversion can be seen as neutral, but pointing out to a greater need for being with people and thus exposure to greater stress [20]. Correlation of conscientiousness with negative stress management strategies might be caused by a higher degree of stress acting on a student with higher demands on his or her success [25].

\section{Conclusion}

This Big Five research realized among university students seeks correlations between individual personality traits and age, sex, field of study, and stress management strategies (SVF-78). Big Five research shows correlations that differ from each other within specific groups of people. The aim is to analyse such correlations and propose further research among university students.

The research has shown that students show a higher score in conscientiousness and the lowest score in openness to experience. Women achieved a higher number of points in conscientiousness, agreeableness, and extraversion. Men showed greater differences in all traits (greater standard deviation) than women. No dependence on age has been detected. Students of technical fields showed higher score in conscientiousness compared to economics students. Positive stress management strategy showed a correlation with all five personality traits, while negative stress management strategies showed correlation with neuroticism, extraversion, and conscientiousness.

\section{Acknowledgements}

The subject-matter article was published as a part of IGS Project- Internal grant competition); Project Number: 8110-009, Order Number: 05IRP014; Project Name: PsychologicalEntrepreneurial competences of university students at IT.

\section{References}

1. Chadyuk, O. NEO Five-Factor Inventory and its Applications in Industrial /Organizational Psychology [online], Available from: https://www.researchgate.net/publication/278026898_NEO_FiveFactor_Inventory_and_its_Applications_in_Industrial_Organizational_Psycholog y (2009)

2. Costa, P. T. \& McCrae R. R. NEO Five-Factor Inventory [online], Available from: https://www.researchgate.net/publication/278026898_NEO_FiveFactor_Inventor y_and_its_Applications_in_Industrial_Organizational_Psychology (2005).

3. Costa P. T. \& McCrae R. R. NEO-FFI-3. NEO Five-Factor Inventory-3, [online], Available from: https://www.sigmaassessmentsystems.com/assessments/neofive-factor- inventory-3/ (2010).

4. C. Alonso, E. Romero, Study of the Domains and Facets of the Five-Factor Model of Personality in Problematic Internet Use in Adolescents. International Journal of

5. Mental Health and Addiction. 18, 293-304 (2020).

6. Murray, G., Rawlings, D., Allen, N. \& Trinder, J. NEO Five-Factor Inventory Scores: Psychometric Properties in a Community Sample. Journal Measurement 
and Evaluation in Counseling and Development. 36 (3), 140-149 (2003).

7. J. W. Lace, L. N. Evans, Z. C. Merz, P. J. Handal, Five-Factor Model Personality Traits and Self-Classified Religiousness and Spirituality. Journal of Religion and Health. 59, 1344-1369 (2020).

8. Furnham, A. \& Bachtiar, V. Personality and intelligence as predictors of creativity. Personality and Individual Differences 45, 613-617 (2008).

9. K. A. Lyon, G. Juhasz, L. J. E. Brown, R. Elliott, Big Five personality facets explaining variance in anxiety and depressive symptoms in a community sample. Journal of Affective Disorders. 274, 515-521 (2020).

10. MacLaren, V., Best, L., Dixon, M. \& Harrigan, K. Problem gambling and the fivefactor model in university students. Personality and Individual Differences, 50 (3), 335-338 (2011).

11. Rosellini, A. J. \& Brown, T. A. The NEO Five-Factor Inventory: Latest Structure and Relationships Wth Dimensions of Anxiety and Depressive Disorders in a Large Clinical Sample. SAGE yournal, 18 (1), 27-38 (2010).

12. Craig, A. et al. Psychological and neural correlates of emotional intelligence in a large sample of adult males and females. Personality and Individual Differences 46, 111-115 (2009).

13. Furnham, A. \& Cheng, H. The change and stability of NEO scores over six-years: A British study and a short review. Personality and Individual Differences 144, 105-110 (2019).

14. Saucier, G. Replicable Item-Cluster Subcomponents in the NEO Five-Factor Inventory. Journal of Personality Assessment, 70(2), 263-276 (2010).

15. Stidham, H., Summers, J. \& Shuffler, M. Using the Five Factor Model to Study Personality Convergence on Student Engineering Design Teams. Proceedings of the DESIGN 201815 th International Design Conference (2018).

16. Natovova, L., Chylova, H., Michalek, P. \& Natov, P. Which coping strategies are preferred by students in different modes of study. Efficiency and responsibility in education 2012, 416-424 (2012).

17. Chylova, H. \& Natovova, L. Personality and stress coping at Czech University of Life sciences students. Proceedings of the 15 th international conference efficiency adn responsibility in education (ERIE), 125-131 (2018).

18. Hrebickova, M. \& Urbanek, T. NEO Five-factor personality inventory (according to NEO Five-factor Inventory P.T. Costa and R.R. McCraee. Prague: Testcentrum, s.r.o. (2001).

19. Janke, W. \& Erdmannova, G. Stress management strategies - SVF 78. Praha: Testcentrum, s.r.o. (2003).

20. Prudky, L., Pabia,n P. \& Sima, K. Czech higher education: on the way from elite to universal education 1989-2009. Grada Publishing as (2010).

21. Bunevicius, A., Katkute, A. \& Bunevicius, R. Symptoms of anxiety and depression in medical students and in humanities students: Relationship with big-five personality dimensions and vulnerability to stress. International Journal of Social Psychiatry 54, 494-501 (2008). 
22. Mlcak, Z. Five-factor model of personality, prosocial behavior and empathy in high school and university students. Social processes and personality (2010).

23. Noftle, E. E. \& Fleeson, W. Age differences in big five behavior averages and variabilities across the adult life span: Moving beyond retrospective, global summary accounts of personality. Psychology and Aging, 25(1), 95 (2010).

24. Jarkovska, L. \& Liskova, K. Gender aspects of Czech education. Sociological journal 44, 683-701 (2008).

25. Komarraju, M., Karau, S. J. \& Schmeck, R. R. Role of the Big Five personality traits in predicting college students' academic motivation and achievement. Learning and individual differences, 19(1), 47-52 (2009).

26. Trapmann, S., Hell, B., Hirn, J. O. W. \& Schuler, H. Meta-analysis of the relationship between the Big Five and academic success at university. Zeitschrift für Psychologie/Journal of Psychology, 215(2), 132-151 (2007). 